Finisterra, XXVIII, 55-56, 1993, pp. 255-259

\title{
POLÍTICAS DE DESENVOLVIMENTO ECONÓMICO LOCAL NA EUROPA E NOS ESTADOS UNIDOS DA AMÉRICA ${ }^{(1)}$
}

CARLOS NUNES SILVA ${ }^{(2)}$

A crise e as transformações operadas na década de 80 nas economias desenvolvidas dos 2 lados do Atlântico estiveram na base de experiências diversas de intervenção dos poderes públicos na promoção do desenvolvimento económico local.

Bennett e Krebs para o caso britânico e alemão e Bartik para o caso norte-americano dão-nos conta de experiências e resultados neste domínio, muito úteis para uma reflexão sobre o caso português no momento em que termina a aplicação do P.D.R.- Quadro Comunitário de Apoio (1989-1993) e se prepara o lançamento do $2^{\circ}$ Quadro Comunitário de Apoio (1994-1999).

São dois trabalhos sobre a mesma problemática mas muito diferentes nos objectivos e na concepção: o texto de Bennett e Krebs vale sobretudo pelo questionamento dos paradigmas vigentes e pela definição de rumos alternativos, nesta altura já não inovadores, a partir de uma sólida abordagem empírica, enquanto o de Bartik, sendo ainda

(1) Bennett, R.J.; Krebs,G. (1991) - Local economic development: public-private partnership initiation in Britain and Germany, Belhaven Press, London

Bartik, T.J. (1992) - Who benefits from state and local economic development policies?, Upjohn Institute, Michigan

(2) Assistente da Faculdade de Letras de Lisboa, colaborador do Centro de Estudos Geográficos, Faculdade de Letras de Lisboa, 1699 Lisboa Codex. Tel. (351-1) 7940218 - Fax (351-1). 
mais pobre no plano da reflexão teórica, vale sobretuđo pela metodologia utilizada na medição dos efeitos práticos das políticas públicas.

Bennett e Krebs, na linha de trabalhos anteriores, desenvolveram a sua abordagem empírica com base nesta tese: devido às transformações demográficas, económicas, sociais e técnicas associadas a uma mudança na forma de encarar o Estado-Providência e a função e. necessidades do mercado, não é razoável aceitar que a política de desenvolvimento económico local seja um exclusivo das autarquias locais (autoridades públicas). Por conseguinte, prosseguem os autores, as políticas de desenvolvimento e animação económica têm necessariamente que assentar em formas flexíveis de parceria (partenariado) entre os poderes públicos (autarquias locais e administração central) e os agentes privados (empresários e respectivas estruturas associativas).

Em suma, para Bennett e Krebs, esta abordagem permite usufruir das vantagens das abordagens «top down» e das «bottom up», mas a sua configuração tem que ser específica para cada área, tese que partilhamos inteiramente e que não parece estar a ser devidamente contemplada pela administração central e Comunidade Europeia, em Portugal.

Bartik aborda esta problemática de um ângulo diferente: procurou avaliar empiricamente os efeitos das políticas públicas, local e estatal, no crescimento económico e os efeitos redistributivos das mesmas, confrontando-as aqui e ali com uma possível intervenção federal. A sua tese central é que as políticas públicas do Estado federal e de cada um dos outros Estados devem considerar as especificidades locais (das áreas metropolitanas, áreas rurais, outros «locais») e, por conseguinte, devem ser territorialmente discriminantes. É uma tese aceite na Europa, nos meios académicos e políticos, nomeadamente na Comunidade Europeia, mas que nos Estados Unidos tem tido alguma oposição por parte da Administração, inclusivé na do Presidente Carter.

O teste empírico das suas hipóteses é feito ao longo de 6 capítulos (cap.2 a 7) e, no capítulo 8, discute o efeito conjugado das intervenções das autoridades locais (metropolitanas p.e.) e dos Estados. No capítulo 2 (p.17-62), Bartik faz uma revisão da bibliografia sobre os impactos das políticas públicas de promoção do desenvolvimento 
económico local, o que é muito útil no apoio ao ensino em disciplinas que versem a gestão do território. Nos capítulos 3 a 7 (p.63-186), o autor desenvolve a análise empírica das suas hipóteses de trabalho após apresentar teoricamente o seu modelo de interpretação e avaliação dos impactos, no capítulo 3 .

As principais conclusões a que chegou foram:

(a) existe evidência empírica que corrobora o crescimento da actividade económica (volume de negócios) consequência das medidas de desenvolvimento desencadeadas pelos poderes públicos («autarquias» e Estados): medidas fiscais (incentivos fiscais) e a melhoria dos serviços públicos às empresas;

(b) a evidência empírica corrobora a hipótese de o crescimento económico local apoiado se repercutir positivamente no número de empregos e na redução da taxa de desemprego local a longo prazo;

(c) o crescimento económico apoiado teve efeitos mais positivos no crescimento dos rendimentos dos indíviduos pretos e dos que têm níveis de escolaridade mais baixo, porque melhoraram as suas qualificações profissionais, mas não teve efeitos significativos nos níveis de desemprego;

(d) a competição que se desenvolve entre as várias áreas («autarquias») contribui positivamente para uma redistribuição da actividade económica em favor das áreas menos desenvolvidas, ao mesmo tempo que reduz o desemprego e melhora a produtividade e níveis de inovação das actividades privadas; mas Bartik encontrou elementos que lhe permitem concluir pela existência de uma transferência do rendimento nacional em favor dos detentores dos meios de produção, circunstância que poderá ser compensada por uma política fiscal assente em taxas progressivas.

A partir desta verificação o autor discute as implicações destas tendências e reflecte sobre os custos e benefícios reais destas intervenções dos poderes públicos locais.

A primeira ideia é que, apesar dos efeitos positivos que têm sobre o crescimento da actividade económica e este sobre o emprego, nem todas as medidas e programas têm um balanço custo - benefício positivo. Na maior parte dos casos, os benefícios limitam-se a compensar os custos, e é nas regiões mais deprimidas (com elevadas taxas de desemprego) que a criação apoiada de emprego tem efeitos mais positivos. Por isso, Bartik advoga que, em áreas onde o desemprego 
(subemprego) não atinge níveis calamitosos, os programas de intervenção devem privilegiar medidas de criação de postos de trabalho com um custo baixo por cada emprego criado. Neste ponto a contribuição mais inovadora de Bartik é a verificação da não existência de comprovação empírica de resultados positivos claros por parte do novo tipo de medidas que ele designa de «nova vaga» (basicamente inovação tecnológica, modernização, criação de empresas), ao contrário das medidas tradicionais (incentivos fiscais, prestação de serviços públicos incluindo criação de infraestruturas) com efeitos positivos empiricamente comprovados.

Outra questão levantada é o facto de as políticas públicas terem privilegiado o lado da oferta (formação profissional, educação) e descurarem o lado da procura (subsídios aos salários, emprego nos serviços públicos) por forma a maximizar a procura de emprego. Esta crítica é também válida para algumas das políticas de desenvolvimento económico local que entre nós se têm desenvolvido.

O livro termina com vários apêndices (p.213-330), um dos quais é uma síntese dos resultados obtidos pelos trabalhos recenseados, útil como documento de apoio ao ensino.

Em suma, se quisermos destacar um ponto com maior interesse neste livro, ele é sem dúvida o conjunto de orientações que dá sobre critérios de avaliação das políticas públicas de desenvolvimento económico local.

O trabalho de Bennett e Krebs também foca as acções de desenvolvimento económico (criação de riqueza e empregos) no contexto de mercados de emprego locais, mas fá-lo por um outro prisma: o dos actores envolvidos nesse processo e das formas de cooperação (parceria) entre eles, tomando como pano de fundo as transformações na estrutura territorial e produtiva em economias de mercado desenvolvidas (Reino Unido e R.F.A.).

A segunda tese que enforma o livro é relativa ao conceito central deste projecto de investigação: não só os factores de produção mas também os actores envolvidos na sua utilização e gestão têm que se juntar em estruturas que garantam o sucesso e a continuação do desenvolvimento económico local, ou seja, a cooperação ou parceria (partenariado) é o elemento chave do desenvolvimento auto-sustentado, o que não significa que todos os agentes têm igual importância nesse processo. 
E é o desenvolvimento desta dimensão que constitui o corpo do trabalho de Bennett e Krebs: nos capítulos 2 e 3, as causas e racionalidade da intervenção, nos capítulos 4 a 6, o contexto institucional para estas intervenções, no Reino Unido e na Alemanha e, nos capítulos 7 a 11, abordam formas de parceria em diferentes sectores (desenvolvimento de recursos humanos, desenvolvimento empresarial, gestão urbanística). No capítulo 12 , perspectivam esta abordagem para o futuro próximo.

Não obstante o mérito do trabalho há aspectos que suscitam alguma reserva: a representatividade dos casos estudados, a definição do conceito de parceria e a delimitação dos casos a considerar dentro dessa categoria, e o excessivo pendor empirista da abordagem adoptada. Ao contrário de Bartik, Bennett e Krebs não nos dão uma avaliação dos impactos destas formas de organização do desenvolvimento local e não questionam a adequação das mesmas aos casos em causa nem as confrontam com alternativas.

Não obstante estas reservas, os dois textos analisados constituem um valioso contributo para o conhecimento das políticas de desenvolvimento económico local e os resultados a que chegaram podem ser pontos de referência na definição de futuras intervenções. 